\title{
Rapid Climate Adaption Assessment (RCAA) of water supply and sanitation services in two coastal urban poor communities in Accra, Ghana
}

\author{
Nikolaus Clemenz ${ }^{1}$, Richard Boakye ${ }^{1}$, Alison Parker ${ }^{1 *}$ \\ 1. Cranfield Water Science Institute, Cranfield University, Cranfield, MK43 0AL, United \\ Kingdom \\ * corresponding author: a.parker@cranfield.ac.uk
}

\begin{abstract}
This study assessed the impact of different hydrological scenarios on existing vulnerabilities of water and sanitation services in Chorkor and Shiabu, two coastal urban-poor communities in Accra, Ghana. The hydrological scenarios were developed from the literature on climate change projections. This paper recommends adaptations for community members, service providers and the municipality based on the impact assessment.

Chorkor and Shiabu are vulnerable to an increase in rainfall because of the lack of adequate solid waste management and hydrological sound drains. Shiabu's topography and the indiscriminate sand mining along its beach make it vulnerable to an increase in sea-level. Looking beyond Chorkor and Shiabu's community boundaries, the urban water utility which supplies water vendors in both communities may be severely impacted by a decrease in rainfall, which would lead to water scarcity and a shortage in hydroelectricity.

Regardless of which climate change scenario emerges, many of the recommended adaptations are good water management practice, for example increasing the number of household connections and reducing non-revenue water. Putting climate change high on the agenda has the potential to generate additional funding to help address Chorkor and Shiabu's water and sanitation problems, and climate-proof services for the future. However the study method does not address the governance of these adaptations and this is a limitation.
\end{abstract}

Keywords: Climate change adaptation / climate change impacts / urban-poor / water / sanitation / Accra / Ghana 


\section{INTRODUCTION}

Increasing concerns over climate change and its impacts continue to fuel a global debate on how to increase resilience and adapt to a changing climate. The impacts of climate change are likely to vary geographically and across societies. While it is difficult to make concrete projections, it is expected that the poor in low- and middle income countries, especially in Africa, will be affected most (Boko et al., 2007). This is because climate change places additional pressure on countries which often lack sufficient economic resources and already face challenges such as rapid urbanisation and environmental degradation (Boko et al., 2007; IPCC, 2007).

On a global level, climate change alters the hydrological cycle, which makes water one of the primary media through which climate impacts the earth's ecosystems and human wellbeing (UN Water, 2010). Therefore, water resources and the water and sanitation sector is expected to be particularly impacted by climate change (Bates et al., 2008; UN Water, 2010).

The importance of access to and availability of safe water and sanitation was highlighted by the United Nations' affirmation of the right to water and sanitation and its Sustainable Development Goal Six (SDG 6) (United Nations, 2015a). However, despite a series of high-level reports on climate change and water and sanitation there is a striking lack of context specific and pragmatic advice on adaptation measures for water and sanitation service providers (Oates et al., 2014). One attempt to fill this gap was made by Heath, Parker and Weatherhead in 2012, who developed the Rapid Climate Adaptation Assessment (RCAA). This paper represents a further application and testing of the RCAA .

Africa's capacity to adapt to climate change is reduced because of a combination of multiple stresses including "endemic poverty, complex governance and institutional dimensions; limited access to capital, including markets, infrastructure and technology; ecosystem degradation; and complex disasters and conflicts" (Boko et al., 2007, p.435). These existing vulnerabilities are exacerbated by population growth and urbanisation. This makes Africa the continent most vulnerable to the impacts of climate change (Parry et al., 2007).

In contrast to the rest of the world, population growth across Africa continues to accelerate. The United Nations Population Division (UNPD) estimated that by 2050, Africa's population will have doubled to 2.4 billion (UNPD, 2015). Most of this growth takes place in urban areas, and as the most rapidly urbanising region in the world, Africa is projected to see a $16 \%$ rise to $56 \%$ of its population living in is cities by 2050 ( UNPD, 2015). Ghana follows this trend.

As at 2015, 54\% of Ghana's population live in urban areas in which $38 \%$ of the population live in slums (The World Bank, 2016a). It is the urban poor, often living in informal settlements which are unplanned and densely populated, who are most vulnerable to climate change in Ghana (Agyemang-Bonsu, et al., 2009). In Accra (a rapidly growing coastal city of roughly three million people) these settlements are often located along the coastal areas or close to surface watercourses where sea-level rise, induced by climate change, and heavy rain events, are likely to exacerbate periodic flooding (Brown et al 2011; Rain et al., 2011). 
A very conservative estimate based on Ghana's 2000 census suggested that in Accra 172,000 residents are at risk of a 10-year flood from channel overflow (Rain et al., 2011). There have been warnings that at the low-lying coastal environments in the west of Accra, the coastline could recede $202 \mathrm{~m}$ from 1970-1990 levels by the year 2100 due to sea-level rise. This could displace 26,000 people by the year 2050 and 646,000 people could be affected by inundation by the year 2100 (Appeaning Addo et al., 2011). Sea-level rise is also likely to cause saline intrusion of seawater into the groundwater (Brown et al 2011; Rain et al., 2011).

Increasing temperatures could also cause additional public health risks as disease vector distribution patterns shift (Agyemang-Bonsu, et al., 2009). Furthermore, with climate change increasing, temperatures are likely to increase evaporation, leading to lower water levels in Accra's surface water reservoirs, on which the city mainly relies for its piped water (Abankwa et al., 2009).

According to the WHO/UNICEF Joint Monitoring Program (JMP), 93\% of Ghanaians living in urban areas have access to an improved water supply (WHO/UNICEF, 2015). However, only $20 \%$ of the urban population has access to improved sanitation. Another $73 \%$ use shared facilities (public toilets, compound toilets) and an estimated 7\% openly defecate.

However, due to a mix of "technical, institutional and social constraints" (Van Rooijen, et al 2008, p.1) Ghana Water Ltd (GWCL), Ghana's urban water utility, is only able to meet $63 \%$ of Ghana's urban demand and only $45 \%$ of Accra's urban population have a piped household or yard connection (Van Rooijen et al 2008). GWCL has introduced a drinking water rationing program for Accra, to address the issue of demand outstripping supply. This leaves $75 \%$ of Accra with an intermittent water supply (Water Aid, 2008). While the percentage of the urban population with access to an improved water source has increased from $84 \%$ in 1990 to $93 \%$ in 2015 , the percentage with access to piped water has decreased from $41 \%$ to $32 \%$ over the same period (WHO/UNICEF, 2015). Together with existing vulnerabilities in water and sanitation, achieving universal access to water and sanitation is increasingly at risk as climate change impacts water resources and services (Howard and Bartram, 2010).

This paper describes the application of the RCAA to two coastal urban-poor communities in Accra: Chorkor and Shiabu. The objectives were:

- to conduct the first study applying the RCAA methodology to a coastal city, where water and sanitation services are likely to face challenges such as increasing sea-level, coastal erosion, salinisation of groundwater and subsidence of land; and

- to make recommendations on how to increase service resilience, considering current vulnerabilities in water and sanitation and the impact of future hydrological scenarios. 


\section{Background}

\section{Chorkor and Shiabu}

Chorkor and Shiabu are located alongside the western coastline of Accra (Map 1). Chorkor and Shiabu have an area of $\sim 0.5 \mathrm{~km}^{2}$ each and it is estimated that around 15,000 people live in each of the two communities. They used to be an isolated fishing villages that are now part of the urban area (Engstrom et al 2013) 

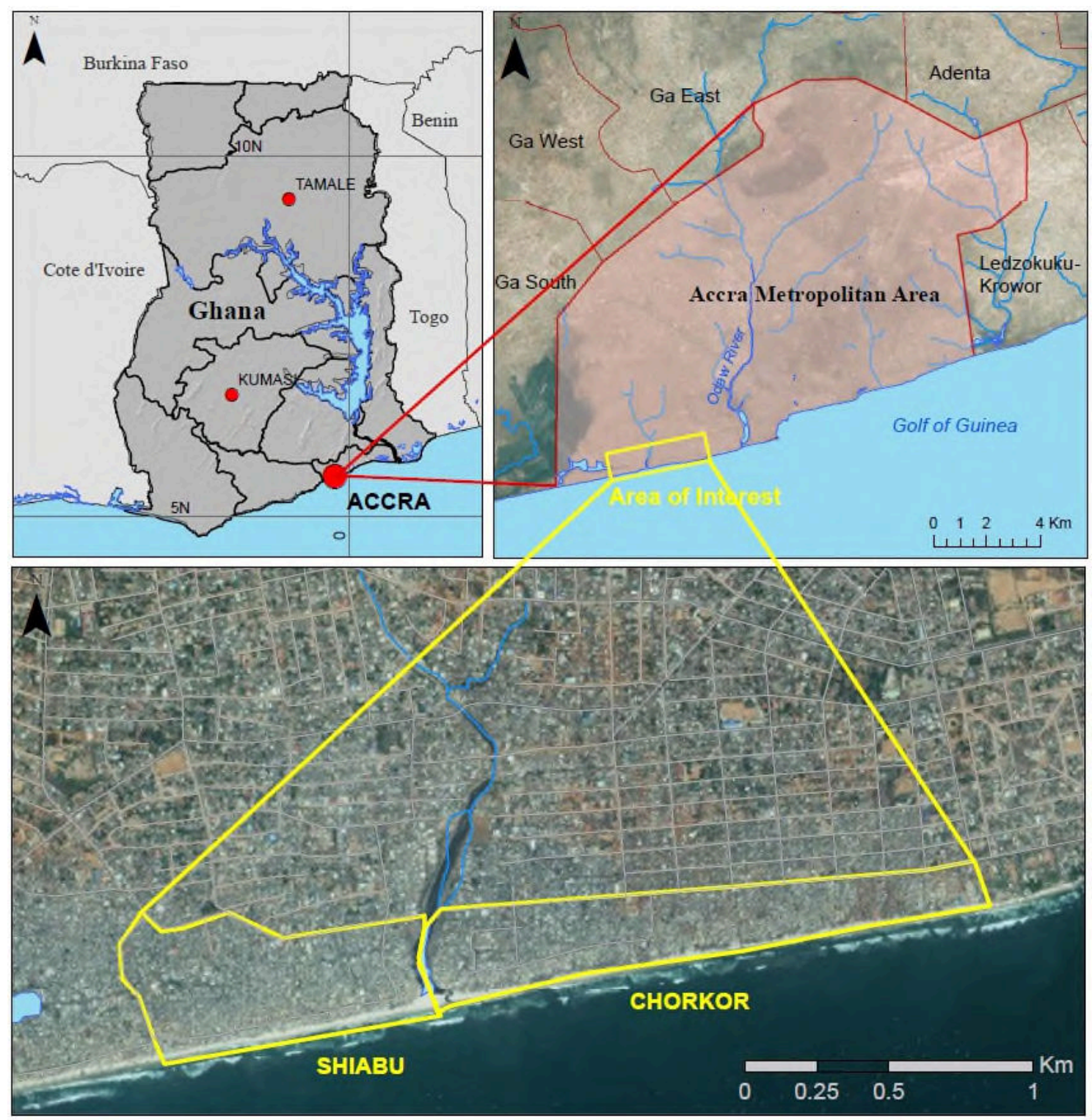

Map 1: Overview map Chorkor and Shiabu (OSM, 2015)

The Accra-Tema Metropolitan Area (ATMA) is supplied with piped water from three water treatment plants: Weija (Densu river), Kpone (Akosombo dam) and a desalination plant at Nungua in the Kpeshie district. However, it is estimated that only 45\% of Accra's urban population have a piped household or yard connection (Van Rooijenet al 2008). Most people in Chorkor and Shiabu are supplied with water by private water vendors who receive water from the Weija treatment plant, via GWCL. This is the most common supply situation in Accra (Abankwa et al., 2009). Population growth is as high as $9 \%$ in the urban fringe, and water supply lags behind 
population growth; the gap in 2008 was estimated to be $47 \%$, although it might be less due to the contribution of informally operated boreholes (van Rooijen et al 2010).

The water from the water vendors is usually used for household purposes and personal hygiene. It is sometimes used for drinking, although studies have shown that in Accra's slum neighbourhoods, $50 \%$ of households, particularly those with lower incomes, use sachet water from shops and street vendors for drinking (Stoler et al., 2012). This was confirmed by statements made in the focus groups. The water supply is being expanded into Chorkor by the $\$ 150$ million Greater Accra Metropolitan Area (GAMA) Sanitation and Water Project; this project also aims to increase the provision of environmental sanitation (GWCL 2017).

In Chorkor and Shiabu the majority of the population relies on privately run "public toilets", while some defecate at the beach. Household toilets are rare and they are not sewered.

\section{Climate change}

McSweeney et al. (n.d.) projected that Ghana's mean annual temperatures will increase by 1.0$3.0^{\circ} \mathrm{C}$ by the $2060 \mathrm{~s}$, and $1.5-5.2^{\circ} \mathrm{C}$ by the $2090 \mathrm{~s}$. This largely corresponds with projections by Minia (2008) and Stanturf et al. (2011). Predictions regarding rainfall remain less certain: half of the models project an increase in rainfall, whereas the other half of the models project a decrease (McSweeneyet al, n.d.; Minia, 2008; as summarised in Stanturf et al., 2011). Stanturf et al. (2011, p.34) forecast that by 2080 "precipitation for Accra and the coastal Savannah zone [will] range from a $52 \%$ decrease to a $44 \%$ increase in wet season rainfall". However, some research predicts that even without climate change considerations Ghana will become a water stressed country by 2025 (Kankam-Yeboahet al 2010). One and five day rainfall maxima tend to increase (MESTI, 2015).

McSweeney et al. (n.d.) projects an increase in sea-level from 1980-1999 levels, of between 0.13 $\mathrm{m}$ to $0.56 \mathrm{~m}$ by the $2090 \mathrm{~s}$, depending on the emission scenario. 


\section{METHODS}

The RCAA was selected for this study because it is a bottom-up approach which allows local stakeholder and communities to inform the recommendations, rather than being more theoretical (van Aalst et al., 2008). An alternative is the CRiSTAL methodology (International Institute Sustainable Development, 2012) but the RCAA is developed specifically for water and sanitation. A review by Doczi (2014) said the RCAA "supports practical program-level decisions on planned adaptation interventions specifically for the water sector". RCAA assesses how climate change will "interact with existing vulnerabilities in peri-urban and informal areas, and then recommends adaptations to the existing plans for water and sanitation providers to increase their climate resilience" (Heath, Parker and Weatherhead, 2012, p.621). It does not seek to perform detailed hydrological or impact modelling but rather provides an overview, bringing key issues to the attention of stakeholders.

This study applied the RCAA in a new context. The RCAA was first proposed by Heath et al (2012) who developed and trialled it in Zambia, Kenya and Madagascar. The methodology assesses existing infrastructural vulnerabilities and the impact of climate change on urban water and sanitation services, and then generates recommendations for local adaptations.

RCAA combines a desk based literature review of key climate change resources with fieldwork in local communities. The RCAA consists of five steps:

1) literature review;

2) vulnerability assessment through fieldwork;

3) hydrology scenario development;

4) impact assessment; and

5) climate proofing recommendations.

\section{Literature review}

A review identified six key national climate change documents in order to identify climate projections for Ghana and develop likely hydrological scenarios for Accra: MESTI (2001), Minia (2008), MESTI (2011), Stanturf, J.A. et al.(2011) The World Bank (2016b) McSweeney et al (n.d.).

\section{Fieldwork - vulnerability assessment}

The fieldwork was undertaken in Accra from the in June and July 2016. It was conducted in two coastal urban-poor communities in Accra: Chorkor and Shiabu. 
Semi-structured interviews, focus group discussions and direct observation were used to assess the current vulnerabilities of water and sanitation services and stakeholders' perceptions of the sustainability of current water resource quality and quantity. 46 semi-structured interviews were conducted with stakeholders at national, municipal and community level and two focus groups were conducted at community level. A summary of the interviewees is found in table 1 .

At national level, representatives from ministries, government agencies, development partners, NGOs and researchers were interviewed. At municipal level, interviews were conducted with representatives from Accra's Metropolitan Assembly (AMA), municipal departments, GWCL; and local field officers from government agencies.

At community level, the local chiefs (often land owners) and district assembly man (elected or appointed members of the district assembly (PoG, 1994)) were interviewed. Furthermore, a community focus group was conducted for each community. The aim of the focus groups was to understand the communities' perception of the impact of climate change on communities and their suggestions as to adaptations. 8-10 people were invited to each focus group by the local community leader, with the aim for an equal ratio of men and women, but in practice 16-18 people attended. A local Ga speaking translator facilitated the groups.

Table 1 Type and number of stakeholder interviewed

\begin{tabular}{lccc}
\hline Stakeholder & National/municipal level & Chorkor & Shiabu \\
\hline Community leaders/elders & - & 3 & 1 \\
Community focus groups & - & 1 & 1 \\
Local service providers $^{1}$ & - & 4 & 5 \\
Utility $_{\text {Municipality }}$ & 3 & & 1 \\
Government & 2 & 4 \\
International Organisations & 7 & \multicolumn{2}{c}{-} \\
Researchers & 7 & \multicolumn{2}{c}{-} \\
NGOs & 3 & \multicolumn{2}{c}{-} \\
\hline
\end{tabular}

The questions varied according to the role and expertise of the interviewee. The topics covered in the interview included:

- Climate change awareness of the interviewee(s);

\footnotetext{
${ }^{1}$ Local service providers included: water vendors, public toilet providers and mixed providers offering toilet and bath house services at the same time
} 
- Impacts of climate change on water and sanitation services: discussion of hydrological scenarios and extreme events and their impact on water and sanitation services;

- Other impacts of climate change (not related to water and sanitation): assessment of the wider impacts of climate change on the communities, such as people's livelihoods, their diet and the communities' infrastructure;

- Water resources: discussion of quality and quantity of surface water and ground water in Ghana, review of abstractions and competing uses, and the identification of major threats such as pollution.

- Existing climate change related policies, strategies, and management plans; and

- Adaptations: discussion of how stakeholders could adapt to long-term climate change and extreme events.

Questions were adapted for each stakeholder group. Verbal statements provided during the interviews and focus groups, were confirmed, where appropriate, through transect walks and direct observations. During observations, special attention was paid to the local topography, and the general state of the local infrastructure, particularly infrastructure related to water and sanitation. Indicators of flooding and sea-level rise such as water marks, water logging and subsidence of land were also identified during observations. Direct observations were documented through pictures and field notes.

Interviews and focus groups were recorded and notes taken during the interviews and focus groups were checked against the recording. The notes were transferred into NVivo, a qualitative data analysis software, which was used for "thematic coding" - coding frequently emerging terms across the data set, and collating them into themes (Boyatzis, 1998; Braun and Clarke, 2006). Initial themes, based on the literature review, were defined before fieldwork was conducted, but were subsequently adjusted to account for themes that had emerged during the fieldwork. The final set of themes formed the basis for the analysis.

\section{Hydrology scenario development}

Variability in climate projections and lack of localised climate projections, necessitated the development of simple conceptual hydrological scenarios. Scenarios were based on data found in climate change literature. The lack of localised quantitative data meant the scenarios were only conceptual in accordance with the rapid nature of the RCAA method Heath et al 2012). These scenarios were tested for potential impacts on the local hydrological regime (groundwater and surface water resources) using the method proposed by Heath et al (2012), with adaptations to account for the coastal location of Chorkor and Shiabu. Scenario testing included an analysis of the following risks:

- increased surface runoff and erosion;

- increased flooding;

- increased groundwater recharge and rise in groundwater levels;

- decreased surface water availability;

- decreased groundwater levels; 
- coastal erosion and flooding;

- saline intrusion into groundwater; and

- subsidence of land.

\section{Impact assessment}

The impact assessment used the information from the vulnerability assessment and considered how the different hydrological scenarios would impact water resource quality and quantity water and sanitation services and the community as a whole. It analysed how projected changes to the climate and hydrology would interact with already existing vulnerabilities by assessing the resilience of both communities' water and sanitation technologies in the projected scenarios. It was important to assess the wider impact of climate change on the community as a whole, since changes to people's livelihoods can affect household income, which can affect affordability of services and willingness to pay. In turn, inability to pay could lead to a lack of funding for climate change adaptations (WSUP, 2014).

\section{Climate proofing recommendations}

Adaptations for community members, local service providers, GWCL and the municipality were recommended, based on the results from the impact assessment (which included suggestions from the focus group and interviews) and technology specific adaptations from Vision 2030 (Howard and Bartram, 2010). This approach meant that recommended adaptations were specific to the local context. 


\section{RESULTS}

\section{Hydrological scenarios}

Three hydrological scenarios were developed for Chorkor and Shiabu based on the climate change literature on Ghana. These were (1) increase in rainfall and rainfall intensity; (2) decrease in rainfall; and (3) rising sea-level.

Due to the variability of climate projection the scenarios are qualitative only. These scenarios were used to analyse the impact of climate change on Accra's water and sanitation services.

\section{Awareness of climate change}

During the interviews, national stakeholders such as ministries, academia and development partners demonstrated a good understanding of climate change but less showed less understanding of the specific impact of climate change on water and sanitation services. At municipal level only one out of five interviewees had a good understanding of climate change and an awareness of the National Climate Change Policy (NCCP).

Residents in both communities had a relatively high awareness of climate change. For example, the fisherman observed changes in the onset and offset of the rainy season, erratic rainfall patterns and sea-level rise and people mentioned that they cannot dry foodstuffs like cassava in the sun. They also observed the sea coming closer, and believed it was only divine intervention keeping them alive.

\section{Impacts of climate change on water resources}

1. Increasing rainfall: Increasing rainfall would, on the one hand, have a positive effect on groundwater recharge and Ghana's surface water reservoirs. On the other hand, it would increase surface runoff and flooding, resulting in solid waste and contaminants being washed into the surface reservoirs. This would likely increase water treatment costs. Interviews with GWCL suggested that the Weija treatment plant, which supplies Chorkor and Shiabu, already has to deal with poor raw water quality due to "human activities that generate waste, untreated sewage, fertilizer and pesticide runoff” (Water Aid, 2008, p. 36)

Furthermore, GWCL reported that after rain events, high levels of sediment being washed into surface water reservoirs forces them to shut down their treatment plant. In addition, interviewees said that the newly constructed sea-water desalination plant has to be shut off after rain events due to the large amount of solid waste being washed into the sea and choking the intake screen.

2. Decreasing rainfall: Decreasing rainfall would lead to lower water levels in surface water reservoirs and a reduction in hydroelectric production (Kankam-Yeboah et al 2010). This would 
impact the water treatment plant and pumps which require electricity. Thus, a decrease in rainfall is likely to lead to an even more intermittent water supply.

3. Sea-level rise: Sea-level rise could increase the salinity levels of groundwater (Addo, 2013). However, some of Accra's aquifers are already saline and the population relies mainly on surface water (Abankwa et al., 2009; Addo, 2013).

\section{Impacts of climate change on existing vulnerabilities}

1. Increasing rainfall: Shiabu, which translates as "sandhole", would be particularly impacted by increasing rainfall: it is extremely low lying and used to be a sand pit (Map 2). Community members reported frequent flooding, even during minor rainfall events.

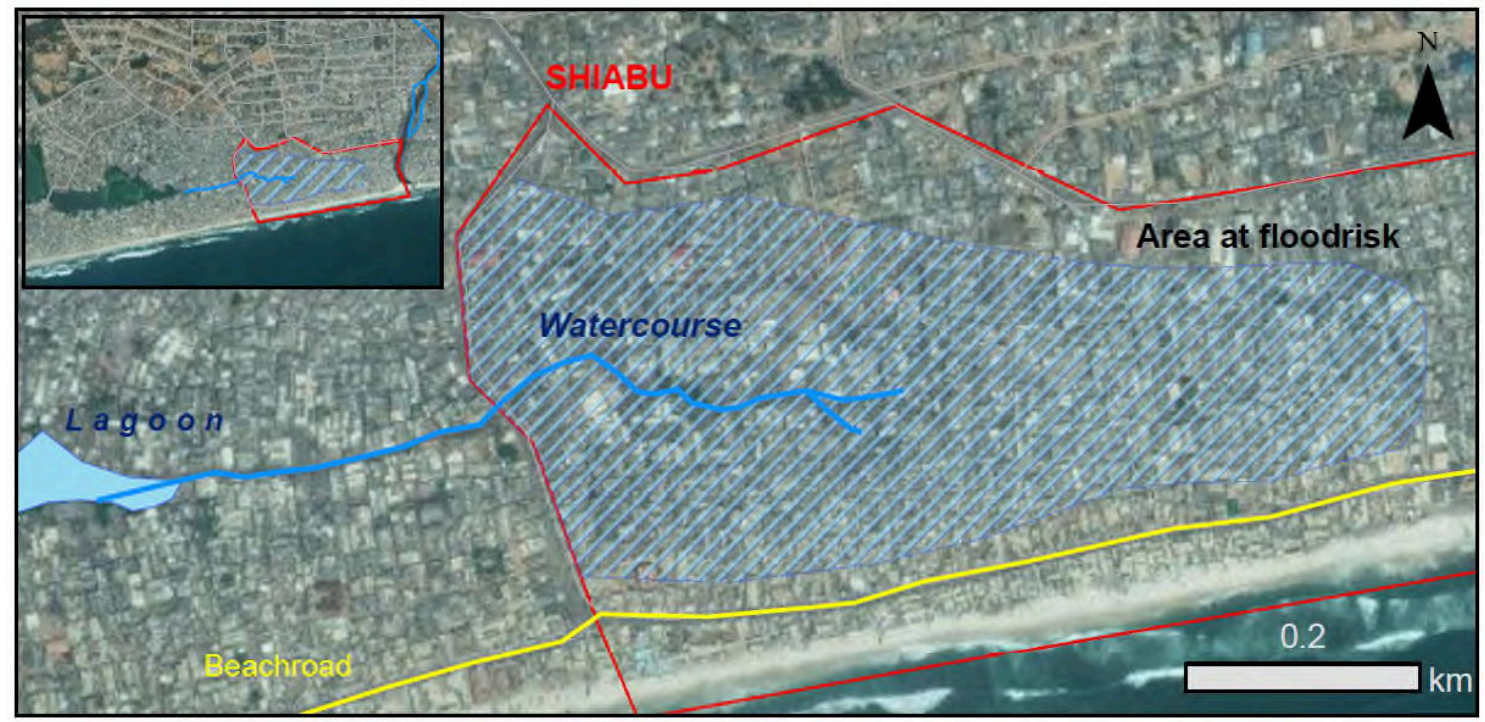

Map 2: Shiabu—flood prone area (assessed by water marks on the houses)

Shiabu's susceptibility to flooding is exacerbated by community members filling up the water course with rubbish to reclaim land for construction (Figure 3). 


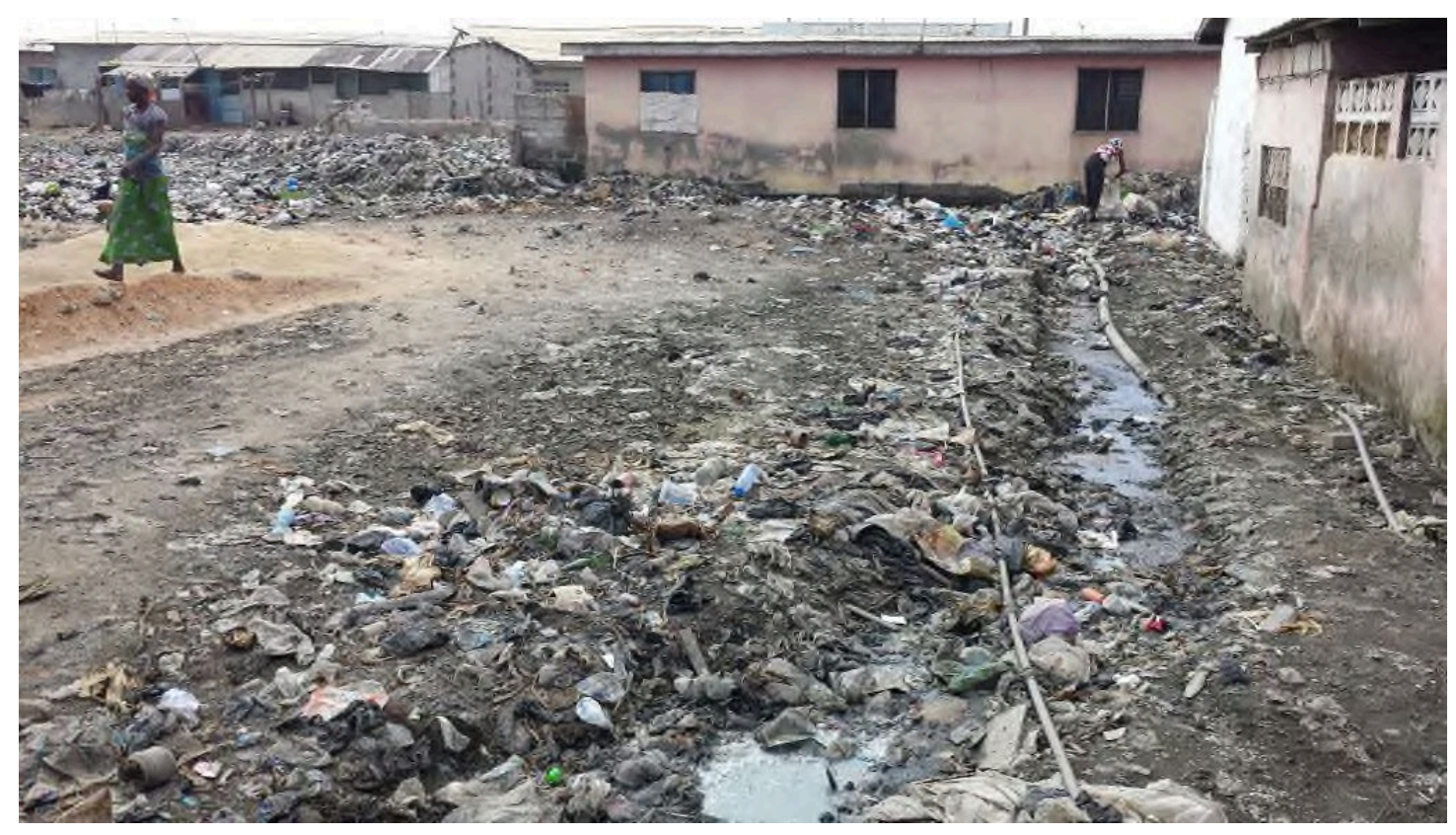

Figure 3: Watercourse filled up with rubbish and water marks on the houses

The watercourse is the only effective drain towards the nearby lagoon. The only other drains are found along the road that runs along the beach ("beach road") which acts as dam between the sea and the community. However, these drains are parallel to the coastline and are insufficiently sloped, as is evident from the stagnant water found days after the last rainfall and accounts from the local National Disaster Management Organisation's (NADMO) field officers (Figure 4). Furthermore, the community often dumps household waste in the drains, leading to the drains being choked. As a result, during rain events these drains often overflow back into the community and cause flooding. Increasing rainfall and rainfall intensity would likely exacerbate this situation. While water and sanitation vendors along the beach road are relatively safe from flooding, vendors within the community frequently see their infrastructure flooded (Map 2). 

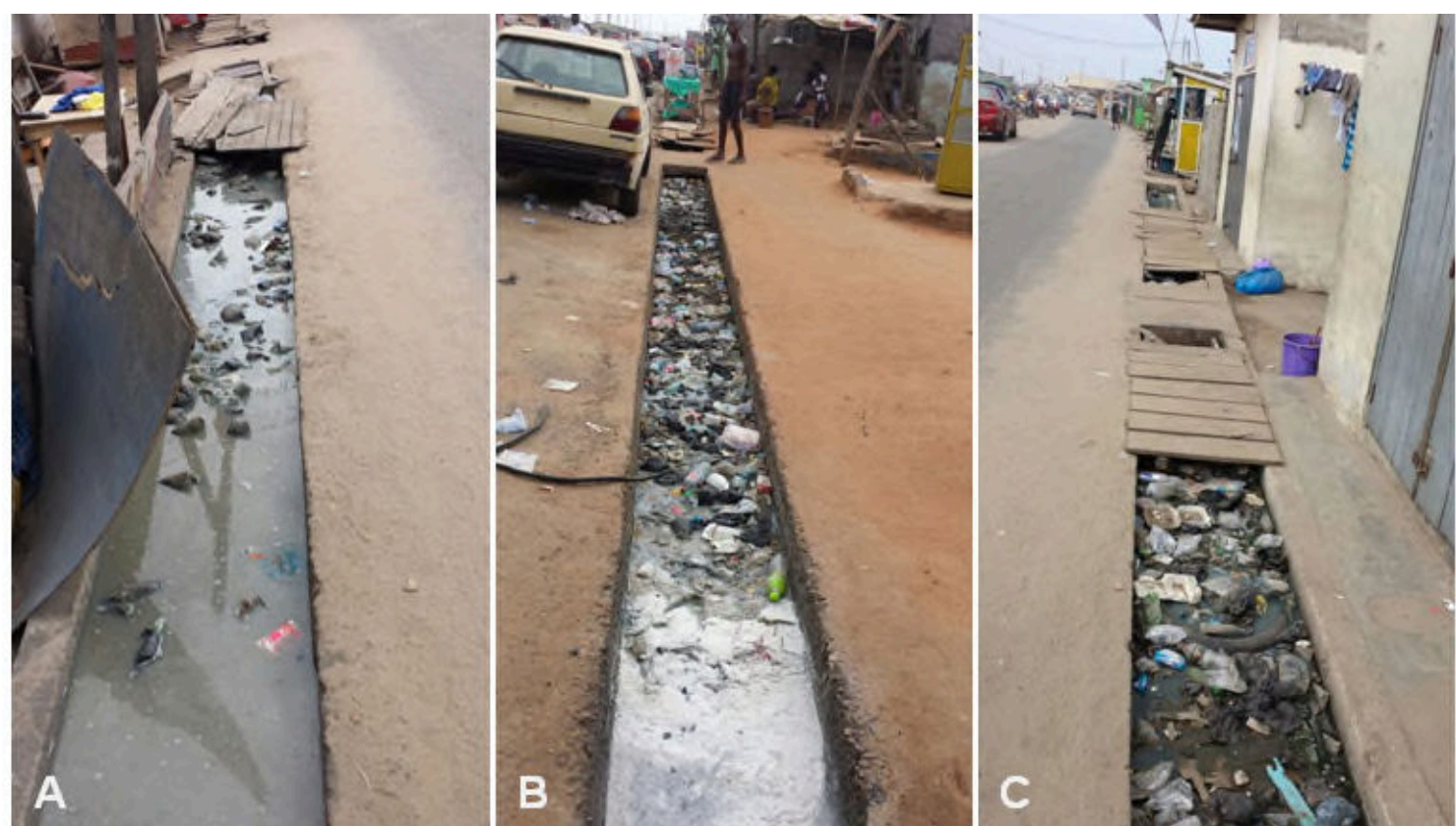

Figure 4: Choked drains in Chorkor (A) and in Shiabu (B \& C)

Flooding causes sediment and garbage to be deposited and block the drain. Overflowing septic tanks and damaged sewers crossing the community can potentially contaminate standing water after flood events and re-contaminate piped water-especially if the water supply is intermittent (Figure 5). 


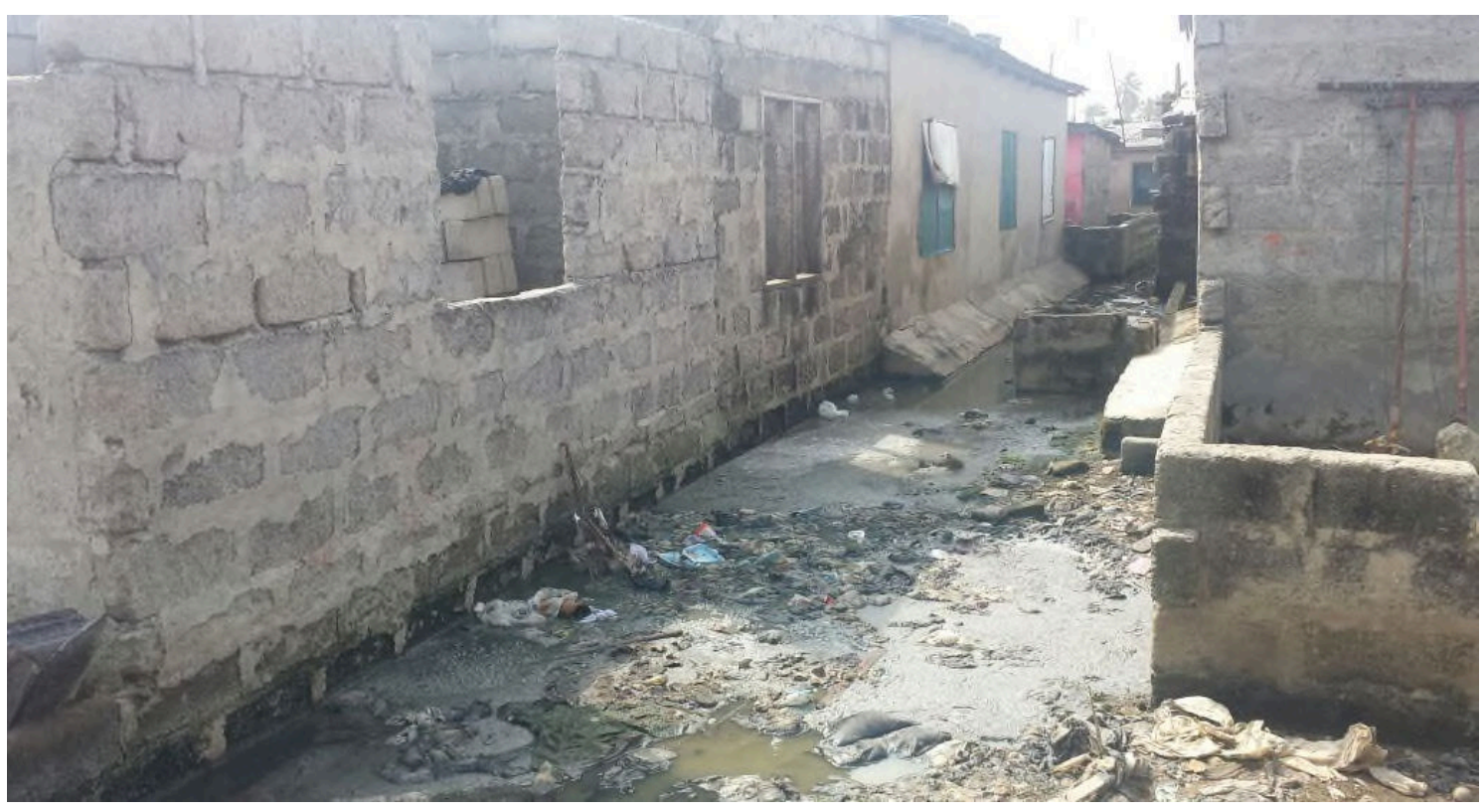

Figure 5: Sewerage from damaged sewer running between houses

Chorkor gently slopes towards the sea, and is therefore not at risk of flooding. However, the part of the community which is located along the coastline has no storm drains. Therefore, increasing rainfall would cause intensive surface erosion, exposing pipes and causing damage to the water infrastructure.

Public toilets in both communities are vulnerable to Accra's frequent power outages. All public toilets that were visited were pour-flush toilets, which often relied on boreholes in order to flush the toilets. These boreholes had mechanical pumps, however there was only limited storage capacity available, so that when the power was out some sanitation vendors had to go to the sea to fetch water for flushing. Sanitation vendors described as their main issue the frequent power outages, which are often caused by strong winds during heavy rain events damaging electricity wires.

2. Decrease in rainfall: Neither community was concerned about the effects of a decrease in rainfall. However, they reported frequent power outages during the dry season. While some power outages are related to strong winds, others are connected to decreasing levels of hydroelectric productivity during the dry season (Agyemang-Bonsu, et al., 2009). Although Ghana's energy issues are complex and not solely related to climate change, a decrease in rainfall would likely exacerbate the situation. This would particularly affect sanitation service providers who use groundwater from boreholes for flushing their toilets. The community could also be affected by a reduced availability of drinking water.

3. Increase in sea-level: An increase in sea-level and saline intrusion would have no direct impact on local water resources, as the community only uses groundwater, for flushing the public toilets 
as it is already saline. However, combined with a receding coastline, increasing sea-levels would destroy houses and infrastructure close to the existing shore line. Both communities lie in an area with a high vulnerability to coastal erosion, with a historic erosion rate of $1.50 \mathrm{~m} / \mathrm{yr} \pm 0.17 \mathrm{~m} / \mathrm{yr}$ (Addo 2013). The trend is likely to continue due to sea-level rise, a deficit in sediment budget for littoral transport and anthropogenic activities such as sand-mining (Appeaning Addo et al., 2011, Addo, 2013). Due to its geology (mainly unconsolidated alluvial sediments) and its extremely low-lying topography, Shiabu is more vulnerable than Chorkor to coastal erosion and flooding.

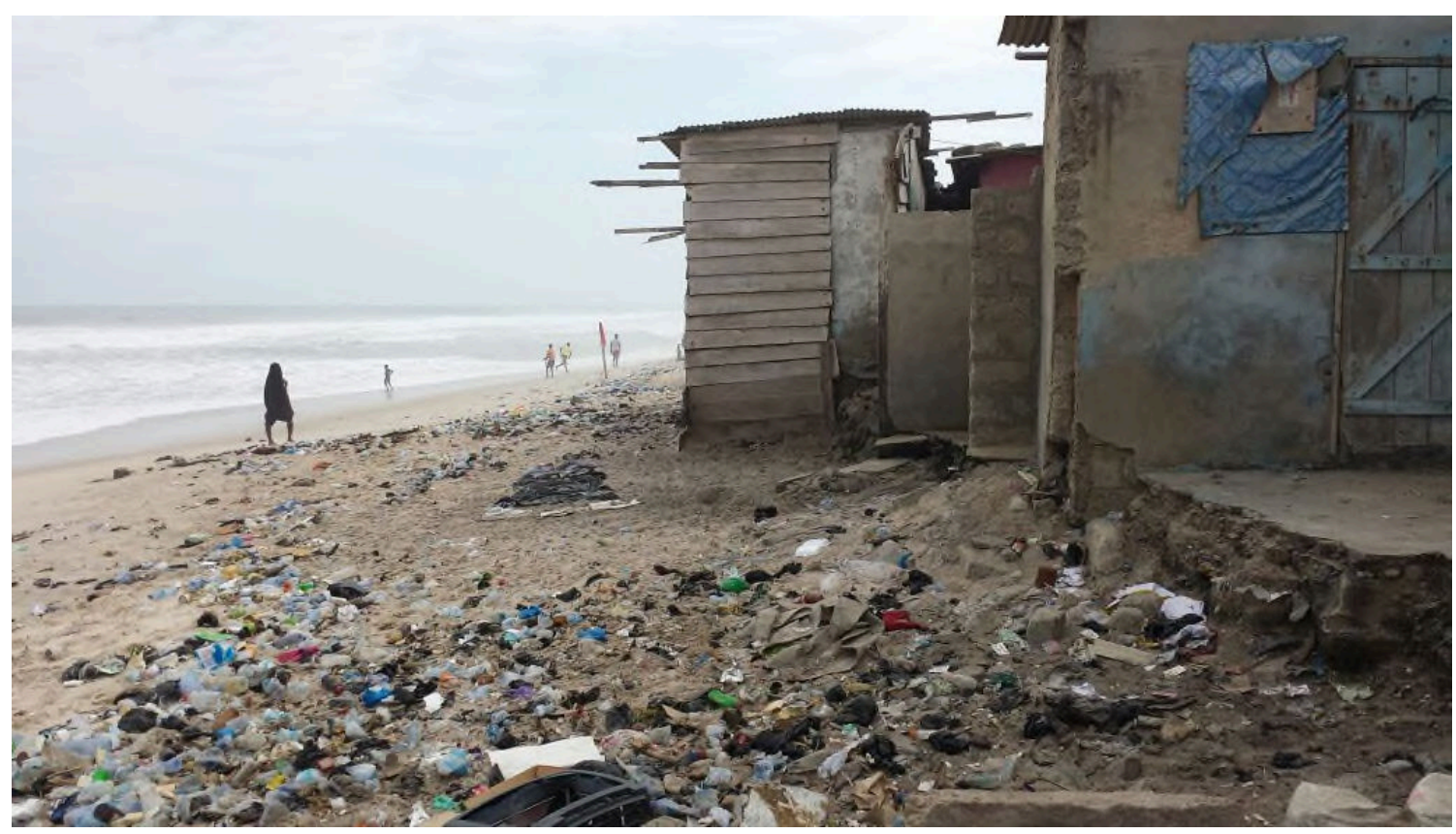

Figure 6: Foundation eroded by seawater (Shiabu)

Shiabu's residents and the local chief confirmed that the row of houses closest to the coast was destroyed by waves, within the last two years, and the sea has come gradually closer over the past 30 years.

\section{Other impacts of climate change on the communities}

Fishermen reported that during the rainy season a lot of sediment is washed into the sea, and that this, along with plastic waste which gets caught in their nets, reduces their catch. An increase in rainfall intensity is likely to exacerbate this problem.

A reduction in rainfall and an increase in temperature in the north of Ghana has resulted in a reduction of crop yields. Interviewees stated that the scarcity of certain crops has resulted in a change of their diets. It has also forced many people who rely on farming to migrate into urban centres in order to find a job (Abankwa et al., 2009; Rain et al., 2011). This migration is one of 
the major causes of urbanisation and slum development in Accra and increases the pressure on land and infrastructure in communities like Chorkor and Shiabu.

\section{Climate proofing recommendations}

Climate proofing recommendations have been developed for four main stakeholders: community members, local service providers, GWCL and the municipal government. Since many of the impacts and vulnerabilities are interrelated, recommendations tackling the same issue may target various stakeholders. It should be noted that the RCAA does not consider the available resources which is a clear limitation. Nevertheless, the recommendations should be useful to help stakeholders prioritise actions.

1. Increasing rainfall: Both communities described increasing rainfall as the main threat to the community, with the potential to exacerbate surface runoff and localised flooding. However, it appears that the actual threat is not increasing rainfall in and of itself, but the underlying issue of the lack of adequate drainage and poor solid waste management.

The RCAA made the following recommendations to address an increase in rainfall:

- Municipalities should incentivise residents to bring their waste to the communal collection points instead of dumping waste on the road, in the drains or on the beach.

- Local water and sanitation service providers should protect their infrastructure from surface flow in order to prevent infrastructural damage and, in the case of water vendors, contamination of the stored water.

- The municipality, together with local waste collection services, should provide enough collection points to encourage appropriate waste disposal.

- The municipality should monitor the performance of the waste collection contractors, formalise the role of tricycle collectors and enforce existing law on illegal waste disposal.

- The municipality should rehabilitate the existing drains and build new drains in both communities. In Chorkor and Shiabu, additional drainage is required to drain access water from the "beach road" into the sea. Shiabu is also in urgent need of a drainage channel directing water into the lagoon, to prevent flooding.

- The municipality should dredge and stabilise the existing water course, which acts as a natural drain, and prevent people from filling it up with rubbish to reclaim land.

The recommended measures are likely to reduce the pollution of ground and surface water, reduce surface runoff and flood risk and prevent the re-contamination of drinking water.

2. Decreasing rainfall: This paper makes the following recommendations to address a decrease in rainfall:

- Residents should consider increasing household storage capacity and harvest rain water to prepare for water shortages.

- Water vendors should also increase safe storage capacity and treat stored water. 
- The owners of public toilets which rely on boreholes should invest in a generator to mitigate the effect of power outages-likely to increase in frequency if rainfall decreases.

- GWCL should consider climate change in the planning and design of its treatment and distribution infrastructure.

- GWCL should reduce non-revenue water, which is currently at 50\% (personal communication GWCL), in order to save water and increase its revenue. This revenue could be used to subsidise a pro-poor tariff and thereby increase the number of people with a household connection.

3. Sea-level rise: Sea-level rise and increased coastal erosion will impact both communities. However due to its topography Shiabu may be hit hardest.

This paper makes the following recommendations to address a rise in sea-level:

- Community members should stop constructing houses along the beach and stop sand mining.

- NADMO should provide education on the consequences of sand mining and enforce the ban on this activity.

- The municipality should consider relocating people in the long-term, in addition to its plans to construct a sea-defence. 


\section{Increasing rainfall and increasing rainfall intensity}

Impact: Surface runoff and flooding causes damage to water and sanitation infrastructure, spreads liquid and solid waste in the community, washing litter, sediments and contaminants into surface water reservoirs

- Dispose solid waste at public waste collection points

- Stop flushing faeces on the roads

- Clean drains

- Stop building in flood prone areas

- Consider household water connection
- Account for climate change in planning and design

- Assess infrastructure at flood risk

- Monitor water quality during flooding

- Improve coordination with the water resources commission for source protection
- Improve urban drainage system

- Improve solid waste collection

- Enforce urban bylaws

- Build capacity at a sub-metro level to monitor contracts with water and sanitation service providers

\section{Decreasing rainfal}

Impact: Decreasing groundwater and surface water availability; decrease in hydroelectric production; increase in competing water demands due to increasing irrigation needs

- Increase capacity for household storage

- Consider a household connection
- Increase water storage capacity

- Treat stored water

- Take action to reduce spillage at taps

- Invest in a generator
- Account for climate change in water resource planning

- Rehabilitate pipe network, reducing nonrevenue water

- Increase energy efficiency of treatment plants

- Introduce a truly 'pro-poor' tariff

\section{Increasing sea-level}

Impact: Coastal erosion, destroying infrastructure; increasing coastal flooding; saline intrusion into groundwater

- Stop sand mining
- Stop constructing alongside the beach
- Identify infrastructure at risk of sea-level rise
- Investigate inter-basin water transfers

- Improve efforts to educate regarding water use
- Enforce the existing spatial plan

- Plan for relocation of residents 


\section{DISCUSSION}

Heath et al. (2012) found that community members often had a little awareness of climate change. However, fieldwork in Chorkor and Shiabu suggests that coastal fishing communities may represent a special case. Residents in both communities, particularly fisherman, were found to have a relatively high awareness of climate change. This could be explained by the fact that they are exposed to the daily weather and are affected by seasonality. Indeed, Yaro (2013), observed that Ghanaian farmers, also affected by the weather and seasonality, have "clear ideas of the trends in the parameters of climate change".

Both communities perceived themselves as particularly vulnerable to an increase in rainfall and rainfall intensity. They did not see themselves as vulnerable to a decrease in rainfall. However, the water and sanitation technology in both communities are vulnerable to both an increase and decrease in rainfall.

The piped water system which supplies the water vendors in both communities is vulnerable to a range of impacts, due to its large spatial extent and different components. Upstream water scarcity may lead to a reduction in bulk water production due to water and electricity shortage, while flooding is likely to wash sediments and contaminants into the Weija reservoir. Downstream, distribution pipes may be damaged by flooding, leading to contamination of drinking water. It should also be acknowledged that the inability of the GWCL to increase water supplies at the same rate as urbanisation (van Rooijen et al 2010) means that population growth is may be having a bigger effect than climate change, an argument also put forward by Carter and Parker for Africa (2009).

Septic tanks, which use water for flushing, may be impacted by a drying environment, whereas the current flooding situation already leads to overflowing septic tanks and widespread environmental contamination. These findings are confirmed by the general technology assessment in Vision 2030 (Howard and Bartram, 2010).

The community's belief that they are more vulnerable to an increase in rainfall and rainfall intensity may result from the fact that localised flooding already poses a major challenge. Furthermore, an increase in flooding would cause more immediate damage to infrastructure at community level than the other scenarios. Nonetheless, research shows that both scenarios are equally likely (Kankam-Yeboah, Amisigo and Obuobi, 2010; McSweeneyet al n.d.; Stanturf et al., 2011).

Boakye (2018) compared the preliminary findings from this study to two other low income coastal communities in Accra where the RCAA methodology was also applied: Glefe and Jamestown He found the services and vulnerabilities were similar except that Chorkor and Shiabu had no bath stalls and which he attributed to the greater population density in these communities.

Ghana's high inter-annual variability (MEST, 2015) leads to uncertainty in climate change projections and therefore makes it challenging to manage surface water and groundwater (Oates et al., 2014). However, many of the recommendations provided in this study are simply good water management practice, and their implementation would aid water and sanitation management and climate proofing, regardless of which climate change scenario occurs. For example, if GWCL were to reduce its high level of non-revenue water, this would, on the one hand, enable GWCL to adapt to a decrease in rainfall, while on the other hand, generating revenue which could be used to subsidise a pro-poor tariff. The introduction of a truly pro-poor tariff would be significant, as "the lifeline", a reduced tariff, has increased in cost in 2015 by $69 \%$ and the eligible allowance was reduced from $20 \mathrm{~m}^{3}$ to $5 \mathrm{~m}^{3}$ (PURC, 2015). The cost of water is even higher for those who are unable to afford access to a pipe connection: research has shown that in Accra, those who buy water from water vendors are likely to pay 4-18 times more than users with 
a regular connection (Van Rooijenet al 2008). There is a \$150million World Bank project to expand the water network and increase the provision of environmental sanitation, but these efforts will only affect Chorkor, not Shiabu (GWCL 2017) There is an estimated $\$ 327$ million annual funding gap required to meet the Sustainable Development Goal for Water in Ghana (Safe Water Network 2017), so even this investment is still woefully inadequate.

Ghana ratified the UNFCCC in 1995. It submitted its first, second and third communication in 2000, 2011 and 2015 respectively. Within Ghana's Government MESTI and EPA are the key institutions that implement and coordinate climate change related policies and programs (MESTI, 2015).

In order for the recommendations to be successful they to be need to be integrated into the existing policy framework (Sanchez-Rodriguez, 2009; Simon, 2010). This is the major limitation of the RCAA methodology: while it is a suitable tool to identify hydrological scenarios and their impacts it does not address governance, policy and finance related issues. It was evident from the fieldwork that Ghana's vast legislative and executive portfolio on climate change is not translated into real actions.

There are a range of complex reasons for this, from a lack of government prioritisation (Arthur, 2015), through to the Government's failure to provide the funding and support to comply with its own the standards and regulation-observed both by Oates et al. (2014) and by a number of interviewees. This is further confirmed by AMA itself which identified "poor governance as the core developmental problem" (AMA, 2016, p.1) and found that its effects, which include "inadequate revenue mobilization" and "low institutional and financial capacity of AMA departments", lead to inadequate service delivery. Furthermore, stakeholders also suggested that Ghana's climate change policies are too generic and fail to meet local needs: one interviewee commented that the policies "look as if they have been written in a hotel room in London". This is borne out by reports that there are "no directives or implementation plans tackling climate related risks at the district level" in Ghana (Delali, Nyamedor and Enoabasi, 2014).

The authors realised that the lack of attention of the RCAA on resource availability and more broadly the governance of adaptation was a major limitation, and decided to further explore it by revisiting some of the stakeholders to discuss their adaptive capacity and build an Adaptive Capacity Wheel, assessing eight dimensions of their adaptive capacity: variety, learning capacity, room for autonomous change, leadership, availability of resources, fair governance, adaptation motivation and adaptation belief (Gupta et al 2010, Grothmann el al 2013). The conclusions are presented in detail in Boakye (2018) and highlight how informal providers are often able to be more nimble and quickly adapt to changing situations, whereas larger organisation are more inflexible. However, the informal sector lacks coordination and their adaptations can compromise services elsewhere, for example water vendors pumping directly from main water pipes. The RCAA methodology is a rapid methodology and does not include detailed scenario development and modelling. However because it is quick and cheap to undertake, it can be completed in low resource settings and can be a practical call to action for stakeholders.

The RCAA methodology does not aim to address governance related issues. However, if applied differently, it could contribute to solving this bottleneck: by sending feedback on local climate change adaptations to national level actors, to enable them to refine national policies. Taking a bottom-up approach could make Ghana's climate change policies less generic and therefore more implementable. Nevertheless, Ghana's political priorities need readjusting: climate change should be mainstreamed into Ghana's water and sanitation policies and into sectoral development plans. Furthermore, sufficient funding at municipal level needs to be sought to enable policy implementation. 
At a time where Ghana's budget is limited and the water and sanitation sector needs significant investment, climate change could pose an opportunity for the introduction of new water and sanitation technologies and for additional funding, given its prominence on the international stage. One interviewee from an international organisation alluded to this idea that climate change could be an agenda for change, suggesting that: "Climate change...has the potential to create a double stream which also allows [for] fixing...[Accra's]...water and sanitation problem". 


\section{CONCLUSION}

For the purpose of this study the RCAA methodology was applied to coastal communities for the first time. Three hydrological scenarios were developed and the impact of the scenarios on water and sanitation services in Chorkor and Shiabu, as well as their direct impact on existing infrastructural vulnerability, and their indirect impact on the communities, was assessed. Based on the results from the fieldwork, development of hydrological scenarios and the impact assessment it is concluded that:

1. Despite the uncertainty involved in making climate projections, climate change is very likely to impact water and sanitation services in both communities. An increase in rainfall and rainfall intensity is likely to exacerbate the already high risk of localised flooding during the rainy season, while a decrease in rainfall, which is equally likely, would particularly affect GWCL's drinking water production. The communities low lying topography means that sea-level rise could lead to a receding coastline inundating large parts of the communities.

2. Residents in coastal communities demonstrated a good awareness of climate change; however the perception of climate change needs to be critically reviewed. During the focus groups community residents did not see themselves as being vulnerable to a decrease in rainfall, which is as likely as an increase, and could lead to water scarcity.

3. Adaptations at the local level are good water management practice and should be implemented regardless of climate change projections.

4. At the regional level, climate change considerations become increasingly important. GWCL should take climate change considerations into account when rehabilitating infrastructure, and in the planning and design of new infrastructure.

5. The RCAA methodology does not address governance related issues but, if used differently, its results could provide valuable feedback about local level issues to policymakers. Ghana's climate change policies have been criticised for being "too generic" and not localised enough, which impedes implementation.

6. Barriers to implementation need to be addressed and policies need to be made implementable. Steps should be taken to put in place funding to address Ghana's array of climate change policies.

7. The prominence of climate change on the international stage means that it could be used as an "agenda for change" in the water and sanitation sector. Placing a stronger emphasis on the impact of climate change on the water and sanitation sector could attract funding from actors concerned about the impacts of climate change. This could enable the funding of climate change resilient technologies.

This paper makes two key recommendations for future research: first localised climate projections for Ghana should be developed, together with risk maps, in order provide a solid baseline for policy makers and effective climate-proofing. Secondly, governance issues at national and particularly municipal level which impede the implementation of climate adaptations and successful water and sanitation service delivery should be investigated.

To conclude, the RCAA methodology is a suitable tool to provide an overview of impact on water and sanitation services at a local level. Climate change may not be the root of many of the vulnerabilities of these services, but will most certainly exacerbate most of them. However, the RCAA needs to be extended to address governance, policy and resourcing issues. The recommendations made in this paper are good water management practices and should be implemented regardless of climate change. However, addressing climate change and putting it high on the agenda has the potential to generate additional funding with which to address Chorkor and Shiabu's water and sanitation problems, while climate-proofing services for the future. 


\section{ACKNOWLEDGEMENTS}

This research was funded by Water \& Sanitation for the Urban Poor. The authors thank WSUP for their support and assistance with the fieldwork. Furthermore, the author would like to thank all interviewed stakeholders and the participants in focus group discussions for their time and co-operation in conducting this research. 


\section{REFERENCES}

Abankwa, V., El-Sioufi, M., Grimard, A., Sommer, K., Kuria, F. and Ghana Women Land Access Trust 2009 In: Ghana: Accra urban profile. F. Kuria, F. (ed.) Nairobi: UNHABITAT.

Addo, K.A. 2013 Assessing Coastal Vulnerability Index to Climate Change: the Case of Accra - Ghana. Journal of Coastal Research, 165(65) 1892-1897.

Agyemang-Bonsu, W.K., Dougherty, B., Fencl, A. and Kemp-Benedict, E. 2009 Ghana Country Report. in The Adaption Continuum - Groundwork for the Future. Devisscher, T. et al. (eds.) Accra: ETC Foundation, 135-155.

AMA 2016 Accra Metropolitan Assembly: Greater Accra Metropolitan Region Problems Analysis., District Sublinks: Problems Analysis http://ghanadistricts.gov.gh (accessed 28 August 2016).

Appeaning Addo, K., Larbi, L., Amisigo, B. and Ofori-Danson, P.K. 2011 Impacts of Coastal Inundation Due to Climate Change in a CLUSTER of Urban Coastal Communities in Ghana, West Africa Remote Sensing, 3(12), 2029-2050.

Arthur, B. 2015 Memorandum to Government of Ghana on 2015 National Budget CONIWAS, Accra

Bates, B., Kundzewicz, Z., Wu, S. and Palutikof, J. 2008 Climate change and Water. Technical Paper of the Intergovernmental Panel on Climate Change. 5th edn. Geneva: IPCC

Boakye, R.O., 2018 Climate change imapcts on urban WASH servies in Ghana, PhD thesis, Cranfield University.

Boko, M., Niang, I., Nyong, A., Vogel, C., Githeko, A., Medany, M., Osman-Elasha, B., Tabo, R. and Yanda, P. 2007 Impacts, Adaptation and Vulnerability. Contribution ofWorking Group II to the Fourth Assessment Report of the Intergovernmental Panel on Climate Change Cambridge University Press, Cambridge UK

Boyatzis, R.E.R. 1998 Transforming qualitative information: Thematic analysis and code development. Thousand Okaes, CA: SAGE Publications Inc.

Braun, V. and Clarke, V. 2006 Using thematic analysis in psychology. Qualitative research in psychology, 3(2), 77-101.

Brown, S., Kebede, A.S. and Nicholls, R.J. 2011 Sea-Level Rise and Impacts in Africa, 2000 to 2100. Southampton: University of Southampton.

Carter R..C., Parker A. 2009 Climate change, population trends and groundwater in Africa, Hydrological Sciences-Journal-des Sciences Hydrologiques, 54(4) Special issue: Groundwater and Climate in Africa, pp 676-689

Delali, B.K.D., Nyamedor, F. and Enoabasi, D.A. 2014 Building coatsal resilience through an integrated approach: Lessons from Ghana Climate \& Development Knowledge Networ (CDKN), Accra 
Doczi, J., 2014. Managing climate risk for the water sector with tools and decision support, In: Climate Change and Water Resources, S. Shrestha, M.S. Babel, V. Prasad Pandey (eds) CRC Press

Engstrom, R., Ofiesh, C., Rain, D., Jewell, H., Weeks, J., 2013 Defining neighborhood boundaries for urban health research in developing countries: a case study of Accra, Ghana, Journal of Maps, 9, 1, 36-42, DOI: 10.1080/17445647.2013.765366

Grothmann, T., Grecksch, K., Winges, M., Siebenhüner, B., 2013. Assessing institutional capacities to adapt to climate change: Integrating psychological dimensions in the adaptive capacity wheel. Nat. Hazards Earth Syst. Sci. 13, 3369-3384. doi:10.5194/nhess-13-3369-2013

Gupta, J., Termeer, C., Klostermann, J., Meijerink, S., van den Brink, M., Jong, P., Nooteboom, S., Bergsma, E., 2010. The Adaptive Capacity Wheel: A method to assess the inherent characteristics of institutions to enable the adaptive capacity of society. Environ. Sci. Policy 13, 459-471. doi:10.1016/j.envsci.2010.05.006

GWCL 2017 Update of GWCL Water Supply Master Plan for GAMA Including the Preparation of Hydraulic Model and Integrated Water Distribution Network, Ghana Water Company Limitd, Accra, Ghana

http://documents.worldbank.org/curated/en/301801494497764849/pdf/SFG3347-RP-

P119063-Box402908B-PUBLIC-Disclosed-5-10-2017.pdf (Accessed 4 April 2019)Heath, T., Parker, a. H. and Weatherhead, E.K. 2012 Testing a rapid climate change adaptation assessment for water and sanitation providers in informal settlements in three cities in sub-Saharan Africa. Environment and Urbanization, 24(2), pp. 619-637.

Howard, G. and Bartram, J. 2010 Vision 2030: The resilience of water supply and sanitation in the face of climate change. Geneva: World Health Organisation (WHO).

International Institute Sustainable Development, 2012. CRiSTAL Users' Manual Version 5 56, Manitoba, Canada

IPCC 2007 Climate Change in Africa - What is at Stake? Geneva: Intergovernmental Panel on Climate Change.

Kankam-Yeboah, K., Amisigo, B. and Obuobi, E. 2010 Climate Change Impacts on Water Resources in Ghana. Decision-Making Support for Coastal Zone Management, Water Resources and Climate Change in Africa. Accra: Ghana National Commission for UNESCO, 65-69.

McSweeney, C., New, M. and Lizcano, G. (n.d.) UNDP Climate Change Country Profile - Ghana.

MESTI, 2001. Ghana's Initial National Communication under the United Nations

Framework Convention on Climate Change, Accra.

MESTI 2015 Ghana's Third National Communication Report to the UNFCCC. Accra: MEST.

Minia, Z. 2008 Climate change scenario development. in W. K. Agyemang-Bonsu (ed.) 
Ghana Climate Change Impacts, Vulnerability and Adaptation Assessments. Accra: Environmental Protection Agency, Ghana, pp. 2-13.

Oates, N., Ross, I., Calow, R., Carter, R. and Doczi, J. 2014 Adaptation to Climate Change in Water, Sanitation and Hygiene: Assessing risks and appraising options in Africa. London: Overseas Development Institute.

OSM 2015 Open Street Map Data Extracts., Further sources as provided by open street map for World imagery: Esri, DigitalGlobe, GeoEye, i-cubed, Earthstar Geographics, CNES/Airbus DS, USDA, USGS, AEX, Getmapping, Aerogrid, IGN, IGP, swisstopo Available at: http://download.geofabrik.de/ (Accessed: 15 July 2015).

Parry, M.L., Canziani, O.F., Palutikof, J.P., Van der Linden, P.J. and Hanson, C.E. 2007 Climate change 2007-impacts, adaptation and vulnerability: Working group II contribution to the fourth assessment report of the IPCC. Cambridge, UK: Cambridge University Press.

PoG 1994 DISTRICT ASSEMBLY ELECTIONS ACT - 1994 (ACT 473). Parliament of Ghana, Accra

PURC 2015 Public Untilities Regulatory Commission-Press realease: Approved Electricity and Water Tarifs Effective 14th December 2015 Public Utilities Regulatory Commission, Accra http://www.purc.com.gh/purc/sites/default/files/press_release_2015_major_tariff_revie w.pdf (Accessed: 25 August 2016).

Safe Water Network 2017 Ghana sector review: Scaling small water enterprises, Safe Water Network, Accra, Ghana

https://

www.safewaternetwork.org/sites/default/files/Sector_Review_2017_Ghana_FullReport _Web.pdf (Accessed 5 April 2019)

Rain, D., Engstrom, R., Ludlow, C. and Antos, S. 2011 Global Report on Human Settlements 2011, in Global report on human settlements 2011. Washington: UNHABITAT, p. 21.

Van Rooijen, D.J., Spalthoff, D. and Raschid-sally, L. 2008 Domestic Water Supply in Accra : how physical and social constraints to planning have greater consequences for the poor, 33rd WEDC International Conference: Access to Sanitation and Safe Water: Global Partnerships and Local Actions; 7 - 11 April. Accra: WEDC, pp. 1-6.

Van Rooijen, D.J., Biggs, T.W., Smout, I., Dreschel, P. 2010 Urban growth, wastewater production and use in irrigated agriculture: a comparative study of Accra, Addis Ababa and Hyderabad, Irrig Drainage Syst 24, pp53-64

Sanchez-Rodriguez, R. 2009 Learning to adapt to climate change in urban areas. A review of recent contributions. Current Opinion in Environmental Sustainability, 1, pp. 201-206. Available at: http://www.sciencedirect.com/science/article/pii/S1877343509000359 (Accessed: 25 August 2016).

Simon, D. 2010 The Challenges of Global Environmental Change for Urban Africa, 
Urban Forum, 21(3), pp. 235-248.

Stanturf, J.A., Warren Jr., M.L., Charnley, S., Polasky, S.C., Goodrick, S.L., Armah, F. and Nyako, Y.A. 2011 'Ghana Climate Change Vulnerability and Adaptation Assessment', Washington: United States Agency for International Development (USAID), p. 258.

Stoler, J., Fink, G., Weeks, J.R., Otoo, R.A., Ampofo, J.A. and Hill, A.G. 2012 When urban taps run dry: sachet water consumption and health effects in low income neighborhoods of Accra, Ghana., Health \& place, 18(2) NIH Public Access, pp. 250-62. Available at: 10.1016/j.healthplace.2011.09.020 (Accessed: 12 August 2016).

The World Bank 2016a The World Bank - Ghana Development Indicators. Available at: http://data.worldbank.org/country/ghana (Accessed: 1 June 2016).

The World Bank 2016b Climate Change Knowledge Portal 2.0. Climate Change

Knowledge Portal For Development Practitioners and Policy Makers.

UN Water (2010) Climate Change Adaptation: the pivotal role of water', UN Water Policy Brief, FAO Water Available at: https://scholar.google.at/scholar?q=Climate+Change+Adaptation\%3A+The+Pivotal+Ro le+of+Water.+Policy+Brief \&btnG $=\& h l=d e \& a s \_s d t=0 \% 2 \mathrm{C} 5 \# 0$ (Accessed: 24 May 2016).

United Nations 2015a Transforming our world: The 2030 agenda for sustainable development. A/RES/70/1. United Nations General Assembly, New York

UNPD 2015 World Population Prospects - Population Division - United Nations., World Population Prospects, the 2015 Revision Available at: http://esa.un.org/unpd/wpp/Download/Standard/Population/ (Accessed: 24 May 2016).

van Aalst, M.K., Cannon, T., Burton, I., 2008. Community level adaptation to climate change: The potential role of participatory community risk assessment. Glob. Environ. Chang. 18, 165-179. doi:10.1016/j.gloenvcha.2007.06.002

Water Aid 2008 Urban Sector Assessment report. Accra: Water Aid.

WHO/UNICEF 2015 Joint Monetoring Program-Update-report-2015.Grojec, A. (ed.) Geneva: Joint Monetoring Programme for Water Supply and Sanitation.

WSUP 2014 The Urban Programming Guide. 2nd edn. Norman, G. (ed.) London: Water and Sanitation for the Urban Poor.

Yaro, J.A. 2013 The perception of and adaptation to climate variability/change in Ghana by small-scale and commercial farmers. Regional Environmental Change, 13(6), pp. 1259-1272. 